\section{RHABDOMYOSARCOMA OF THE CERVIX IN TEENAGERS - IS FERTILITY PRESERVATION A FEASIBLE OPTION?}

${ }^{1}$ Felicia Elena Buruiana, ${ }^{2}$ Bindiya Gupta, 'Kavita Singh. ${ }^{1}$ PanBirmingham Gynaecological Cancer Centre, Birmingham City Hospital; Gynaecological Oncology, Birmingham, UK; ${ }^{2} T$ he Pan-Birmingham Gynaecological Oncology Centre, City Hospital; PanBirmingham Gynaecological Cancer Centre, Birmingham City Hospital; Gynaecological Oncology, Birmingham, UK

\subsection{6/ijgc-2020-ESG0.25}

Introduction/Background Embryonal rhabdomyosarcoma (RMS) of the cervix is a rare entity, encountered mainly in the first two decades of life. The literature consists mainly of case reports and few small case series, and no standard treatment guidelines are available. As this is a disease of adolescence, fertility preservation in well selected cases is of paramount importance.

Methodology We report 3 cases of embryonal RMS of the cervix in adolescents, along with their clinical presentation, histopathological features, diagnosis, management tailored to individual cases.

Results To date, two of the patients have been followed for 5 years and the remaining 1 for 2 years.

They all remained asymptomatic, with no evidence of recurrent disease on clinical examination and MRI.

Conclusion The embryonal type of cervical RMS is the most frequent type in this age group. Cervical RMS have good prognosis as usually they present early due to clinical features of bleeding or a mass protruding through the vagina. It should be considered as differential diagnosis for continuous vaginal bleeding in a teenager and should be investigated appropriately. The patients diagnosed with RMS should be managed by multidisciplinary team at cancer centre for best outcomes. Given the young age at diagnosis, fertility sparing treatment maintaining the oncological safety is of paramount importance and is associated with long term survival.

Disclosures Nil to disclose.

\section{RISK FACTORS FOR MARGIN POSITIVITY IN LEEP}

${ }^{1}$ Ozlem Celik, 'Halise Meltem Batur, ${ }^{1}$ Anıl Can Yalçın, ${ }^{1}$ Nazlı Can Yalçın, ${ }^{2} U t k u$ Akgör, ${ }^{2}$ Nejat Ozgul, ${ }^{2} \mathrm{M}$ Coskun Salman, ${ }^{2}$ Murat Gultekin. ${ }^{1}$ Hacettepe University Faculty of Medicine; Department of Obstetrics and Gynecology; ${ }^{2}$ Hacettepe University Faculty of Medicine; Department of Gynecological Oncology

\subsection{6/ijgc-2020-ESGO.26}

Introduction/Background Loop electrosurgical excision procedure (LEEP) is the most frequently used therapeutic approach in pre-invasive cervical diseases. Surgical margin positivity is a big debate among gynecologists and there are several reports showing the importance of HPV 16-18, pap-smear results, age of the patient, or size of the lesion. This study evaluates the risk factors for surgical margin positivity among patients who were subjected to LEEP for pre-invasive cervical lesions in a tertiary colposcopy center.

Methodology Patients with pre-invasive cervical lesions who underwent LEEP were retrospectively evaluated. Patients who were not tested for high-risk HPV were excluded. Patients were evaluated for margin positivity with respect to pap-smear result (normal vs. $\geq$ ASC-US), age ( $\leq 40$ vs. $>40$ years), lesion size $(\leq 2$ $\mathrm{cm}$ vs. $>2 \mathrm{~cm})$ and HPV type (16-18 vs. other high-risk HPV). Student-t test and chi-square test were used for comparison.
Abstract 346 Table 1 Comparison of LEEP margine positive vs. negative cases

\begin{tabular}{|l|c|c|c}
\hline & $\begin{array}{c}\text { Margine positive (+) } \\
\mathrm{n}(\%)\end{array}$ & $\begin{array}{c}\text { Margine negative }(-) \\
\mathrm{n}(\%)\end{array}$ & $\mathrm{p}$ \\
\hline Age (mean) & 41,4 & 40,5 & 0,4 \\
\hline Age & & & 0,5 \\
\hline$\leq 40$ & $39(49,4)$ & $130(53,7)$ & 0,5 \\
\hline$>40$ & $40(50,6)$ & $112(46,3)$ & $<0,001$ \\
\hline Pap-smear & & & $<0,001$ \\
\hline Normal & $21(26,6)$ & $123(51,0)$ & $<0,001$ \\
\hline$\geq$ ASC-US & $58(73,4)$ & $118(49,0)$ & $<0,001$ \\
\hline HPV & & & 0,8 \\
\hline $16+/$-18 & $60(75,9)$ & $105(43,4)$ & 0,8 \\
\hline Others & $19(24,1)$ & $137(56,6)$ & 0,06 \\
\hline Lesion size & & & $180(74,4)$ \\
\hline$\leq 2 \mathrm{~cm}$ & $58(73,4)$ & $62(25,6)$ & \\
\hline$>2 \mathrm{~cm}$ & $21(26,6)$ & 1,80 & \\
\hline Lesion size mean (cm) & 1,99 & 242 &
\end{tabular}

Results A total of 321 patients constituted the study group. Among the study group, 79 (24.6\%) patients had margin positivity. Comparison of this group with 242 (75.4\%) margin negative patients revealed that abnormal pap-smear and HPV 16 and/or 18 positivity were significantly associated with margin positivity (table 1). Pap-smear abnormality ( $\geq$ ASC-US) was seen in $58(73.4 \%)$ of margine positive cases whereas only 118 (49.0\%) with margin negativity had abnormal smear $(p<0.001$, OR: $3.1 ; 95 \%$ CI: 1,7-5,6). This risk association did not differ for different Pap-smear abnormality thresholds (LSIL, HSIL etc). Being positive for HPV 16-18 was also a risk factor for margin positivity $(75.9 \%$ vs. $43.4 \%, \mathrm{p}<0.001$, OR: $4.4 ; 95 \% \mathrm{CI}: 2.45-7.96)$. However, neither age $(p=0.5)$ nor the lesion size $(\mathrm{p}=0.8)$ was a significant factor for margin positivity. Among 79 margin positive cases, 33 (41.7\%) had re-LEEP, 13 (16.5\%) had cold-knife conization, $13(16.5 \%)$ had hysterectomy, and $12(15.1 \%)$ were just followed-up while $8(10.2 \%)$ were lost to follow up after the LEEP procedure. Among patients who had re-LEEP or conization $(n=46), 7$ patients $(15,2 \%)$ had still positive surgical margine after the second procedure (5 in re-LEEP $(15,1 \%), 2$ in cold knife conization $(15,4 \%))$.

Conclusion Patients with HPV 16-18 and/or Pap-smear abnormality ( $\geq$ ASC-US) should be carefully evaluated before LEEP procedure for a possible margin positivity. In such cases, larger excisions may be considered to decrease the risk of margin positivity especially if the patient has no future fertility desire.

Disclosures No conflict of interest to declare.

\section{INDUCTION CHEMOTHERAPY FOR LOCALLY ADVANCED CERVICAL CANCER - YAY OR NAY?}

${ }^{1}$ Pedro Simões, ${ }^{1}$ João Godinho, ' Luísa Leal-Costa, ${ }^{1}$ Mafalda Casa-Nova, ${ }^{2}$ Fernando Igreja ${ }^{2}$ Gustavo Mendinhos, ${ }^{3}$ Rosa Madureira, ${ }^{4}$ Vanessa Monteiro, ${ }^{5}$ Vera Mendonça, ${ }^{1}$ José PassosCoelho. ${ }^{1}$ Hospital Beatriz Ângelo; Medical Oncology; ${ }^{2}$ Hospital Beatriz Ângelo; Obstetrics and Gynaecology; ${ }^{3}$ Hospital Beatriz Ângelo; Pathology; ${ }^{4}$ Hospital Beatriz Ângelo; Radiology; ${ }^{5}$ Centro Hospitalar Lisboa Norte, Hospital de Santa Maria; Radiotherapy

\subsection{6/ijgc-2020-ESGO.27}

Introduction/Background Definitive concurrent chemoradiation $[\mathrm{dChR}]$ is the standard treatment for locally advanced cervical cancer [LACC]. Although there's insufficient clinica evidence to support it, induction chemotherapy [iChT 
previous to dChR may reduce the tumour burden and improve symptoms. We evaluated the overall survival [OS] (primary outcome), the complete radiological response rate [CRRR] and the disease-free survival [DFS] (secondary outcomes) of the patients [pts] treated with iChT+dChR at our institution.

Methodology This is a Portuguese, single-centre, retrospective cohort study, including all LACC pts treated with QRTd between 2012 and 2019. The control group received dChR and the experimental group $\mathrm{iChT}+\mathrm{dChR}$. Standard uni/multivariate analyses were performed, with logistic regression models assessing the impact of iChT on CRRR, and Cox regression models for OS/DFS.

Results 57 pts (median age 53yo, 90\% squamous cell carcinoma) were included; 1 with FIGO IB2 stage, 3 IB3, 1 IIA2, 28 IIB, 5 IIIB, 11 IIIC and 8 IVA; 45 were treated with $\mathrm{dChR}$ and 12 with iChT $+\mathrm{dChR}$ (carboplatin/paclitaxel, median 3 cycles). FIGO staging was higher in the iChT $+\mathrm{dChR}$ group $(\mathrm{p}<0.001)$. One patient progressed during iChT, and all others were treated with dChR (1 with carboplatin, 55 with cisplatin, median 6 cycles/66.6Gy); 39\% were treated with brachytherapy boost [BT]. The response rate was evaluable in 51 pts ( 5 died before radiological evaluation and 1 was waiting for it at the time of inclusion). The CRRR was lower in the $\mathrm{iChT}+\mathrm{dChR}$ group (42\% vs $76 \%$, $\mathrm{p}=0.03$ ), but not after adjusting for age, FIGO stage and BT use $(p=0.06)$. With a median follow-up of 49 months, 23 pts died (33\% of the dChR group and $67 \%$ of the iChT $+\mathrm{dChR}$ group): 13 due to progression, 3 due to treatment complications (radiation enterocolitis, pelvic fistulization/ abscess), and 7 due to other causes. In univariate analysis, both DFS (median 11.3 vs 80.2 months, HR 5.8, p<0.001) and OS (median 22.2 months vs NR, HR 3.4, p=0.006) were lower in the $\mathrm{iChT}+\mathrm{dChR}$ group. In multivariate analysis, adjusting for age and FIGO stage, the difference remained significant on DFS $(p=0.01)$ but not on OS $(\mathrm{p}=0.10)$.

Conclusion Pts treated with iChT had worse CRRR, DFS and OS compared with $\mathrm{dChR}$ alone, possibly due to selection bias caused by inclusion of pts with worse prognosis in the iChT group. Although our data does not support the addition of iChT to dChR in LACC pts, it may be considered in symptomatic pts, with urgent need for treatment.

Disclosures Pedro Simões (presenting author) has no potential conflicts of interest to declare.

João Godinho - Scientific Advisory Board: Grunenthal

Luísa Leal-Costa has no potential conflicts of interest to declare.

Mafalda Casa-Nova - Scientific Advisory Board: Roche, Pfizer, Merck; Honoraria received: AstraZeneca, Tesaro, Novartis

Fernando Igreja has no potential conflicts of interest to declare.

Gustavo Mendinhos has no potential conflicts of interest to declare.

Rosa Madureira has no potential conflicts of interest to declare.

Vanessa Monteiro has no potential conflicts of interest to declare.

Vera Mendonça has no potential conflicts of interest to declare.

José Luís Passos-Coelho - Advisory/consultancy: Roche, Novartis, AstraZeneca, Lilly; research Grant/Funding (self): Roche, Novartis

\section{0}

IMPACT OF TREATMENT MODALITY ON SURVIVAL OF FIGO STAGE IIB CERVICAL CANCER: A PROPENSITYSCORE MATCHING ANALYSIS BASED ON IMPACT OF TREATMENT MODALITY ON SURVIVAL OF FIGO STAGE IIB CERVICAL CANCER: A PROPENSITY-SCORE MATCHING ANALYSIS BASED ON SURVEILLANCE, EPIDEMIOLOGY, AND END RESULTS DATABASE

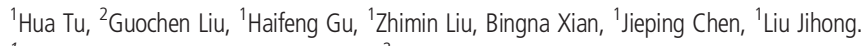
${ }^{1}$ Sun Yat-Sen University Cancer Center; ${ }^{2}$ Sun Yat-Sen University Cancer Center; Department of Gynecologic Oncology

\subsection{6/ijgc-2020-ESG0.28}

Introduction/Background Concurrent chemoradiotherapy is the standard of care for FIGO stage IIB cervical cancer. However, there remains a role of surgical treatment in these patients. The aim of this study was to investigate the impact of treatment modality on survival of patients with stage IIB cervical cancer.

Methodology Patients with stage IIB cervical cancer registered in the Surveillance, Epidemiology, and End Results database between 1988 and 2015 were identified and grouped according to their treatment modalities. For patients identified as surgical group, only those receiving both hysterectomy and chemotherapy were included. For patients identified as non-surgical group, only those receiving both beam radiation and chemotherapy were included. A 1:1 propensity score matching (PSM) were performed to adjust the baseline characteristics.

Results A total of 4718 eligible patients were identified, of whom 902 were in the surgical and 3816 in the non-surgical group. Patients undergoing surgery were younger and were more likely to be married, non-Black race, non-squamous cell carcinoma, N1 stage, and have medical insurance, small tumor compared to those receiving non-surgical treatment $(\mathrm{P}=0.037$ for insurance; $\mathrm{P}<0.001$ for all of others). Before PSM, the surgical group showed significantly improved overall survival (OS) compared with the non-surgical group $(\mathrm{P}=0.005)$, while the difference in cancer-specific survival (CSS) only approached significance $(\mathrm{P}=0.084)$. After PSM, both the differences in OS and CSS between the two groups reached significance $(\mathrm{P}<0.001$, both). In multivariate analysis, the treatment modality was found to be an independent factor for both CSS (hazard ratio [HR] $=1.276, \quad 95 \%$ confidence interval [CI] 1.084-1.502, $\mathrm{P}=0.003)$ and $\mathrm{OS} \quad(\mathrm{HR}=1.312, \quad 95 \% \mathrm{CI} \quad 1.129-1.524$, $\mathrm{P}<0.001)$. Other independent factors for both OS and CSS included histological type, tumor size and N-stage. Age was an independent factor for OS but not CSS. Subgroup analysis revealed that patients receiving radiotherapy prior to surgery had significantly improved CSS compared with those treated by other modalities $(\mathrm{P}<0.001)$, and that the omission of brachytherapy in non-surgical treatment was associated with significantly decreased CSS $\quad(\mathrm{P}<0.001)$. Furthermore, for patients with squamous-cell histology, surgical and non-surgical treatments provided similar CSS $(\mathrm{P}=0.123)$. However, for patients with non-squamous-cell histology, surgical treatments provided significantly improved CSS compared with non-surgical $(\mathrm{P}=0.002)$.

Conclusion The treatment modality has significant impact on survival of patients with stage IIB cervical cancer. Surgical treatment should be preferentially considered in patients with non-squamous-cell histology. Chemoradiotherapy with completion surgery may be the most effective treatment. However, 